Marquette University

e-Publications@Marquette

\title{
Experiences with Benevolent Sexism: Scale Development and Associations with Women's Well-Being
}

Debra L. Oswald

Marquette University, debra.oswald@marquette.edu

Maha Baalbaki

Marquette University

Mackenzie S. Kirkman

Marquette University

Follow this and additional works at: https://epublications.marquette.edu/psych_fac

Part of the Psychology Commons

\section{Recommended Citation}

Oswald, Debra L.; Baalbaki, Maha; and Kirkman, Mackenzie S., "Experiences with Benevolent Sexism: Scale Development and Associations with Women's Well-Being" (2019). Psychology Faculty Research and Publications. 446.

https://epublications.marquette.edu/psych_fac/446 


\title{
Marquette University
}

\section{e-Publications@Marquette}

\section{Psychology Faculty Research and Publications/College of Arts and Sciences}

This paper is NOT THE PUBLISHED VERSION; but the author's final, peer-reviewed manuscript. The published version may be accessed by following the link in the citation below.

Sex Roles, Vol. 80, No. 5-6 (March 2019): 362-380. DOI. This article is (C Springer and permission has been granted for this version to appear in e-Publications@Marquette. Springer does not grant permission for this article to be further copied/distributed or hosted elsewhere without the express permission from Springer.

\section{Experiences with Benevolent Sexism: Scale Development and Associations with Women's Well-Being}

\author{
Debra L. Oswald
}

Department of Psychology, Marquette University, Milwaukee, USA

Maha Baalbaki

Department of Psychology, Marquette University, Milwaukee, USA

Mackenzie Kirkman

Department of Psychology, Marquette University, Milwaukee, USA

\begin{abstract}
Ambivalent sexism theory (Glick and Fiske 1996, 1997) suggests that sexism takes two forms: an overt hostility as well as a subtle benevolence. We examined benevolent sexist behaviors and developed a 25-item Experiences with Benevolent Sexism Scale. Exploratory factor analysis (Study 1, U.S. college sample of 489 women) and confirmatory factor analysis (Study 2, online sample of 216 women) revealed three subscales of benevolently sexist experiences: Heterosexual Intimacy, Protective Paternalism, and Complementary Gender Differences. Women reported experiencing benevolently sexist events more frequently than overtly hostile sexist events;
\end{abstract}


however, they perceived the hostile events to be more distressing and sexist (Studies 1 and 2). Experiencing Protective Paternalism was positively associated with self-doubt and negatively associated with self-esteem (Studies 1 and 2), and psychological well-being (Study 2). However, experiencing Complementary Gender Differentiation was negatively associated with self-doubt and positively associated with self-esteem (Studies 1 and 2), psychological well-being, flourishing, and submission to authority (Study 2). Finally, women in romantic relationships reported more benevolently sexist experiences than did those not in romantic relationships and the frequency of those experiences was positively associated with perceptions of the partner's benevolently sexist attitudes (Study 2). The results highlight that women frequently experience sexism, ranging from overtly hostile to a subtle benevolence, and the different types of benevolent sexism each have unique associations with women's well-being.

Women experience a wide range of sexism in their daily lives. Sexist events are experiences that happen to a woman specifically because of her gender, ranging from daily hassles to stressful life events, and that include both chronic and acute experiences. In a daily diary study, U.S. college-aged women reported experiencing sexist incidents such as being the target of traditional gender-role stereotyping, sexual objectification, and degrading comments (Swim et al. 2001). Klonoff and Landrine (1995) found that $99 \%$ of women reported that they have experienced at least one sexist event in their lifetime and $97 \%$ have experienced sexism in the last year. The most frequently reported events included exposure to sexually degrading jokes, being harassed, being called a sexist name, and being treated with a lack of respect. Younger women, unmarried women, and women from ethnic minority groups were more likely to report experiencing sexist events (Klonoff and Landrine 1995).

When people think about sexism they often focus on experiences such as sexual harassment, assault, and other overtly hostile acts of gender discrimination. However, psychological research suggests that sexism takes two forms: an overt hostility as well as a subtle benevolence (Glick and Fiske $\underline{1996}, \underline{2001 a}, \underline{b}$ ). Hostile sexism reflects hostility directed toward women, especially women who threaten the status quo. In contrast, benevolent sexism reflects a belief that women are weak and in need of protection. Although on the surface benevolent sexism appears to reflect a positive attitude, it is a form of sexism that serves to restrict women to gender-traditional roles. Specifically, this "benevolence" is directed only toward women who are deemed "worthy" because they conform to the traditional gender role. Thus, it functions to restrict women in a narrowly defined, subservient, position. Glick and Fiske refer to these contrasting yet related attitudes and beliefs as benevolent sexism and hostile sexism, and together they constitute ambivalent sexism. Despite their seemingly contradictory positive/negative attitudes toward women, research has consistently found that endorsement of hostile and benevolent sexism is positively correlated (Glick and Fiske 1996, 2001b). In the United States, as well as around the world, endorsement of both hostile and benevolent sexist beliefs is correlated with gender inequality (Glick and Fiske 2001b). Together, these two forms of sexism serve to maintain gender inequality, albeit through two different mechanisms: either bestowing upon women benevolence to "reward" their gender-traditional behaviors or hostility to "punish" their gender non-traditional behavior.

A large body of research suggests that people's endorsement of hostile and benevolent sexist beliefs is associated with negative attitudes and behaviors directed toward women in both their professional and personal lives (Lee et al. 2010). For example, people who endorse hostile sexist beliefs are more likely to negatively evaluate women in work settings (Masser and Abrams 2004; Sakalli-Ugurlu and Beydogan 2002); are less willing to donate to women's organizations, particularly after exposure to sexist jokes (Ford et al. 2008); and are less supportive of women's rights (Masser and Abrams 1999). Endorsement of hostile sexist beliefs is also associated with an increased tolerance of sexual harassment (Russell and Trigg 2004), greater likelihood of engaging in sexually harassing behaviors (Begany and Milburn 2002), and higher proclivity to commit 
acquaintance rape (Abrams et al. 2003). Although benevolent sexism appears to be positive on the surface, it can also limit women's professional success (Jones et al. 2014; King et al. 2012) and is associated with female adolescents' professional and personal future goals being more gender-traditional (Farkas and Leaper 2016). Endorsement of benevolently sexist beliefs is also associated with blaming women who are victims of sexual assaults (Abrams et al. 2003; Chapleau et al. 2007; LeMaire et al. 2016; Viki and Abrams 2002; Viki et al. 2004). Furthermore, women who endorse benevolently sexist attitudes are more likely to accept restrictions placed on their behavior by male romantic partners (Moya et al. 2007; Viki et al. 2003) and describe themselves in relational terms rather than in task-oriented terms (Barreto et al. 2010).

Prior research has examined how hostile and benevolently sexist beliefs correlate with various gendered outcomes. However, how do women's experiences as the targets of these types of sexism impact their lives and well-being? To date, the research examining this question has largely focused on women's experiences with overt sexism. Experiencing overt sexism takes a significant toll on women's mental and physical well-being (Klonoff et al. 2000; Landrine et al. 1995; Moradi and Subich 2002). Klonoff and Landrine's (1995) study using the Schedule of Sexist Events found that the frequency of sexism experienced in the last year and over one's lifetime correlated with a variety of mental health and well-being measures, including depression, anxiety, and somatic symptoms. Furthermore, they found that women's experiences as the targets of sexist events accounted for gender differences in depression, anxiety, and somatic symptoms. Women's experiences with sexism are also associated with increased anger and decreased self-esteem (Swim et al. 2001). These findings suggest that being the target of hostile sexist events has a pervasive, negative impact on women's mental health.

Benevolently sexist experiences pose a unique problem for women because these types of behaviors and attitudes often appear, on the surface, to be warm in nature. Consequently, these behaviors are often difficult for women to identify and challenge as sexist (Becker et al. 2011; Hammond et al. 2014). People more easily identify overt sexism and traditional gender role beliefs as sexist than subtle types of sexism, such as benevolent sexism (Swim et al. 2005). In fact, some research suggests that men who espouse benevolently sexist attitudes are judged somewhat favorably (Barreto and Ellemers 2005; Chisango and Javangwe 2012; Killianski and Rudman 1998). Furthermore, Bosson et al. (2010) found that although people overestimate the amount of distress caused by experiencing hostile sexism, they underestimate the amount of distress caused by experiencing benevolently sexist events. Similarly, people overestimate the recovery time from a hostile sexist event but underestimate the recovery time from benevolent sexism. However, laboratory research has found that women who are experimentally exposed to patronizing behaviors perform worse in stereotypically masculine domains (Gervais and Vescio 2012), are more likely to define themselves in terms of relationships rather than task-oriented characteristics (Barreto et al. 2010), and report more autobiographical memories of incompetence (Dumont et al. 2010). Women who witness a staged act of benevolent sexism also report higher levels of body surveillance and shame (Shepherd et al. 2011).

Yet to be examined are women's everyday experiences as the target of benevolent sexism and how these experiences are associated with their self-concept and well-being. According to ambivalent sexism theory (Glick and Fiske 1996, 2001b), benevolent sexism consists of three interrelated subcomponents: protective paternalism, complementary gender differentiation, and heterosexual intimacy. Protective paternalism refers to attitudes and behaviors that "justify patriarchy by viewing women as not being fully competent adults, legitimizing the need for a superordinate male figure" (Glick and Fiske 1996, p. 493) who serves as a protector. However, they note that "...protective paternalism may coexist with its dominative counterpart because men are dyadically dependent on women (because of heterosexual reproduction) as wives, mothers, and romantic objects; thus, women are to be loved, cherished and protected (their 'weakness' require that men fulfil the protector-and-provider role)" (p. 493). In the Ambivalent Sexism Inventory (Glick and Fiske 1996) this 
component of benevolent sexism is measured with items that suggest that in a disaster women should be rescued before men, "Women should be cherished and protected by men," and that "A good woman should be set on a pedestal by her man" (Glick and Fiske 1996, p. 512). Furthermore, men should be willing to "sacrifice their own well-being in order to provide financially for the women in their lives" (p. 512).

The protective paternalism attitude might be manifested in a variety of behaviors. For example, men who are high in benevolent sexism have been found to provide women with more dependency-oriented support (Hammond and Overall 2015; Shnabel et al. 2016). Dependency-oriented behaviors include "directing or dictating the discussion and the recipient's goal-related plans; neglecting the recipients own abilities" (Hammond and Overall 2015, p. 1182). This results in the recipient's dependency on the helper and undermines the recipients goal-related competence. These types of behaviors could include men telling women what to do, doubting their ability to make good decisions, questioning their expertise, or unnecessarily doing things for women. Other protective paternalistic behaviors could include restricting a women's behaviors because a situation is perceived as not being safe or offering protection (such as being offered a male escort) when it is not wanted or needed under the guise of "safety" (Moya et al. 2007). Women may also be encouraged to look for a romantic partner who is willing to be the financial provider and protector who will "love and cherish" them.

The second component of benevolent sexism, complementary gender differentiation, refers to beliefs that men and women have traits that complement each other and further justifies the traditional division of social roles where women work inside the home and men work outside the home (Glick and Fiske 1996). Often these traits are portrayed as favorable, such as women being viewed as having desirable traits of morality or purity. In the Ambivalent Sexism Inventory this component is measured with items that highlight and praise women's "purity," "superior moral sensibility," and "refined sense of culture and good taste" that men do not have (Glick and Fiske $\underline{1996}$, p. 512). We propose that women's experiences with complementary gender differentiation should have a favorable sentiment where they are encouraged and praised for engaging in gender traditional behaviors expected of a "good woman," such as being moral and displaying purity. Women may be expected to, and praised for, engaging in traditional household labor and childcare (Silvan-Ferrero and Bustillos Lopez 2007). Women may also have experiences where people underestimate or negate their skills and traits that are traditionally associated with a more masculine role, such as agentic traits and physical strength or athleticism.

The third component of benevolent sexism, heterosexual intimacy, reflects men's desire for intimacy and sexual reproduction with women (Glick and Fiske 1996). Heterosexual intimacy romanticizes women as objects of affection and as valued romantic partners. This component was measured in the Ambivalent Sexism Inventory (Glick and Fiske 1996) with items that highlight a man's need for a woman to complete him, that involvement in a romantic relationship is necessary to be happy in life, and that every man should have a "woman whom he adores" (p. 512). Women's experiences with this type of benevolent sexism might include being adored and cherished by a male partner, but also feeling an expectation that they fulfill the partner's intimacy and relationships needs, whether that be through physical, emotional, or sexual intimacy. Indeed, when women interact with a male partner who is high in benevolent sexism they tend to engage in greater relationshiporiented support such as communicating commitment to the relationship, providing affection and emotional support to the partner, supporting the partner's goals, and putting primary emphasis on the partner's success (Hammond and Overall 2015).

In sum, women may experience benevolent sexism as manifested in a variety of ways. The first goal of the current project is to develop and validate a new measure of Experiences with Benevolent Sexism. This new measure is designed to focus on women's experiences across the three subcomponents of benevolent sexism as outlined in ambivalent sexism theory (Glick and Fiske 1997). Second, we seek to examine the frequency that women experience benevolent sexism and the degree to which they view these experiences as sexist and distressing. Third, we seek to test the relationship between women's experiences as targets of benevolent and 
hostile sexism with various measures of self-concept. These goals are tested in two samples: U.S. college-age women (Study 1) and an online sample of women (Study 2).

To develop a potential pool of items for the new measure of Experiences with Benevolent Sexism, we took multiple steps. We examined the items measuring benevolently sexist attitudes on the Ambivalent Sexism Inventory (Glick and Fiske 1996) and wrote new items, when possible, to reflect an experience rather than an attitude. Items from the Chivalry Scale (Viki et al. 2003) that had been revised by Oswald et al. (2012) as a preliminary measure of benevolent sexism were also included in the pool of potential items.

To ensure that the items reflected the range of women's experiences with benevolent sexism, items were also based on essays from a separate study (Baalbaki and Oswald 2017). In that study, 120 college-aged U.S. women ( $M_{\text {age }}=19.02, S D=1.41$, range $=18-29,83 \%$ Caucasian) wrote essays describing a situation in which they, or a woman they observed, was treated unfairly or differently because of her gender. Two coders read the essays and coded them for type of sexism as well as the overall theme of the event. Essays were first coded as describing hostile sexism ( $n=80,66.7 \%)$ or benevolent sexism $(n=30,25 \%)(\mathrm{k}=.94)$ based on Glick and Fiske's ambivalent sexism theory. The benevolent sexist experiences were further coded by subtype $(k=.89) ; 8(6.7 \%)$ were coded as protective paternalism, $11(9.2 \%)$ and were coded as complementary gender differentiation, 9 (7.5\%) were coded as heterosexual intimacy, and two were coded as benevolent sexism but not clearly identified into a subcategory. Essays were also identified as conveying a central theme based on participants' responses rather than on themes imposed by the researchers. The experiences were identified as occurring in the context of sports $(n=7,23.3 \%)$, academics $(n=1,3.3 \%)$, work $(n=5,16.7 \%)$, interpersonal relationships ( $n=11,36.7 \%)$, and other $(n=6,20 \%)$ (coding $\mathrm{K}=.92$ ). Based on these essays, we wrote potential scale items to convey experiences across the different benevolent sexism subcomponents and thematic areas.

Fully 64 items were written for preliminary consideration in the new scale. To narrow the pool of potential items to include only the best items, we took the following steps. First, three researchers (the first author and two researchers not affiliated with the study but who have published research on ambivalent sexism) reviewed all items and selected the ones that they felt best captured the three subcomponents of benevolent sexism. Of these, 51 items were selected by at least one reviewer and were further examined. This set of items was further reduced by eliminating redundant items and items that had severely skewed distributions (based on Study 1). These items had low variability in responses because they were either highly specific situations that few women ever experienced or were so general that everyone had the experience. This process resulted in 28 items that were included in the exploratory factor analysis.

\section{Study 1}

The primary goal of our first study is to develop and test the new Experiences with Benevolent Sexism Scale. We expect to see three factors emerge, consistent with the three subcomponents of benevolent sexism. In exploratory analyses, we also compared the frequency, perceived distress, and rated sexism of these different types of benevolently sexist experiences.

Second, we compared women's experiences with benevolent sexism and hostile sexism. We hypothesize that women will report experiencing benevolently sexist events more frequently than they experience hostile sexist events. However, women will rate their distress and perceived sexism of the benevolently sexist experiences lower than they rate the hostile sexist experiences. This set of hypotheses represents the idea that although experiencing benevolent sexism is common, it is more difficult to recognize as sexist because of the seemingly positive and subtle nature of the events.

Our third goal is to provide preliminary correlational evidence of how experiencing both hostile and benevolent sexism is associated with women's well-being. In the first study, we focus on women's self-esteem and self- 
doubt. We chose to examine these two variables because self-esteem is a central component of a person's selfnarrative and because laboratory evidence suggests that benevolent sexism serves to undercut young women's feelings of self-worth while increasing self-doubt (Dumont et al. 2010; Hammond and Overall 2015). We hypothesize that experiences with both hostile and benevolent sexism will be independently associated with decreased self-esteem and increased self-doubt.

\section{Method}

\section{Participants}

Fully 489 U.S. women participated in the study. Of these, 78\% $(n=381)$ identified being White, $4.5 \%(n=22)$ as African American, $10.2 \%(n=50)$ as Latina, $10.4 \%(n=51)$ as Asian American, and $10.8 \%(n=53)$ indicated another ethnicity. Individuals could check multiple ethnicities as appropriate. Participants were asked to indicate their sexual orientation on a scale of 1 (completely heterosexual) to 7 (completely homosexual). The majority indicated they were heterosexual $(78.5 \% n=384), 9(1.8 \%)$ indicated a completely lesbian orientation, and the rest indicated an orientation ranging in between (with the majority, $n=86$, responding with $2-4$ ). Their mean age was $19(S D=1.07)$ and ranged from 18 to 23 years-old.

\section{Experiences with Benevolent Sexism}

Participants completed the newly developed items to measure experiences with benevolent sexism. The items were assessed on the same scale as the Schedule of Sexist Events (Klonoff and Landrine 1995), ranging from 1 (the event never happened) to 6 (the event happened almost all of [>70\%] the time). The instructions used were the same as in the Schedule of Sexist Events and indicated that participants should rate the extent to which the behaviors occurred specifically because of their gender. Participants completed the items for frequency of experiences in the last year and across their lifetime, as well as appraised the stress associated with the experience, using a scale from 1 (not at all stressful) to 6 (very stressful). Participants also rated how sexist they believed the event to be from 1 (not at all sexist) to 6 (very sexist). The entire pool of developed items was included in data collection, but based on the selection criteria (described previously), 28 items were selected to be included in the factor analysis and subsequent analyses.

\section{Schedule of Sexist Events}

Experiences with overt/hostile sexism were assessed with the Schedule of Sexist Events (Klonoff and Landrine 1995; Matteson and Moradi 2005). This scale includes 20 items reflecting overt and hostile forms of sexism such as intimate/personal sexist events (e.g., "being called derogatory names"; "hearing sexist jokes"; "being made fun of, pushed, shoved hit or threatened with harm"), unfair treatment at work/school ("denied a raise, promotion tenure or other such thing at work"), and unfair treatment in relationships with the events occurring because of their gender. Participants completed the Schedule of Sexist Events three times to assess (a) recent-last year and (b) lifetime frequencies, both rated on a scale of 1 (the event never happened) to 6 (the event happened almost all of [>70\%] the time), and the (c) stressfulness of the experience on a scale of 1 (not at all stressful) to 6 (very stressful). Participants in the current study were also asked to rate how sexist they perceived each behavior from 1 (not at all sexist) to 6 (very sexist). The validity of the Schedule of Sexist Events has been supported by its correlation with other measures of major stressors and daily hassles (Klonoff and Landrine 1995). For the current study, mean scores were computed such that higher numbers indicated increased frequency, distress, and perception of sexism. The Cronbach alphas for the original scale were .90 for Recent-last year, .92 for Lifetime, and .93 for Appraisal (Klonoff and Landrine 1995; Landrine and Klonoff 1997). The Cronbach alphas in the current study were .91 for the Recent-last year, .91 for the Lifetime, .89 for the Appraisal, and .91 for the Sexist versions. 


\section{Self-Esteem}

Rosenberg's (1965) self-esteem measure was used to assess global self-esteem. This is a 10-item measure (e.g., "On the whole, I am satisfied with myself") with participants reporting agreement to the items on a scale of 1 (strongly disagree) to 4 (strongly agree). Items are averaged, and higher scores indicate higher levels of global self-esteem. It has been shown to be valid through positive correlations with other measures of self-esteem and negative correlations with anxiety and depression. In past research, the Cronbach alpha is generally above .80 and has been reported as .88 among U.S. college students and .91 in internet samples representative of the U.S. population (Rosenberg 1965; see Donnellan et al. 2015 for a review). The Cronbach alpha in the current study was .89.

\section{Self-Doubt}

Self-doubt was assessed with two measures. From the Subjective Overachievement Scale (Oleson et al. 2000) we used the Self-Doubt subscale that consists of eight items on a scale of 1 (disagree very much) to 6 (agree very much). This measure of self-doubt was designed "to capture a general sense of feeling uncertain about one's competence" (Oleson et al. 2000, p. 500) and includes items such as "I sometimes find myself wondering if I have the ability to succeed at important activities" and "As I begin an important activity, I usually feel confident in the likely outcome" (reverse scored). It is related to measures of negative affect and concerns about competency, and initial validation resulted in a Cronbach alpha of .82-.83 (Oleson et al. 2000). The Cronbach alpha for the current study was .85.

The Judgmental Self-Doubt Scale, which consists of 19-items, assesses the belief that a person trusts (or mistrusts) her ability to make good judgements (e.g., "I have difficulty making decisions"; "I often don't trust myself to make the right decision") (Mirels et al. 2002). The items were measured on a scale of 1 (strongly disagree) to 6 (strongly agree). The scale previously has been shown to have good internal consistency $(\alpha=.92)$, positive correlations with anxiety and depression, and negative correlations with self-esteem. The Cronbach alpha for the current study was .94.

\section{Procedure}

Participants were recruited from a psychology department subject pool at a midsized, U.S. Midwestern, private Catholic university. At recruitment participants were naïve to the study topic, although the recruitment information indicated that only women could participate in the study. During informed consent, participants were informed that the study was about women's life experiences. Participants completed the measures in a private testing room on a computer. Participants first completed the Schedule of Sexist Events and the newly developed experiences with benevolent sexism items (counterbalanced in the order presented). All other measures were presented randomly, except for the demographics which were always presented last. All participants completed the entire study and were retained for data analysis. Upon completion of the study, participants were debriefed, given their participation cards, and thanked.

\section{Results}

\section{Exploratory Factor Analysis (EFA)}

To examine the scale structure, we conducted an exploratory factor analysis with a promax rotation on the 28 items from the "lifetime" version. We chose the lifetime version of the items for the analyses because the distribution of the items was more normal and showed greater variability than the "last year" version. However, given the strong correlation between the two versions, the results are similar regardless of the version of the scale used in the analyses. To determine the number of components extracted, we conducted a parallel analysis on 500 random samples, examined the scree plot, and considered the interpretability of the components. The scree plot and parallel analysis both indicated three factors. The first three factors were examined and all were interpretable and theoretically meaningful. 
A second EFA was conducted requesting a three-factor solution. Two items (both regarding women's athletic ability and participation) were removed from the analyses because they cross-loaded on two factors. A third item (about people opening doors for women when unnecessary), which did not load onto any factor with a loading of greater than .32, was also removed. A final factor analysis requesting a three-factor solution was conducted (see Table 1a). All items loaded onto one factor with a loading greater than .32. The KMO measure of sampling adequacy was .91 and Bartlett's test of Sphericity was $\chi^{2}(300)=3126.34, p<.001$.

Table 1 Factor analyses of last year experiences with benevolently sexist events, Studies 1 and 2

\begin{tabular}{|c|c|c|c|c|}
\hline Item & $\begin{array}{l}\text { (a) } \\
\text { Study } 1\end{array}$ & & & $\begin{array}{l}\text { (b) } \\
\text { Study } 2\end{array}$ \\
\hline & $\mathrm{HI}$ & CGD & PP & CFA \\
\hline \multicolumn{5}{|l|}{ (a) Heterosexual Intimacy (HI) } \\
\hline You have been put on a pedestal by your romantic partner? & .73 & .04 & -.10 & .41 \\
\hline You have been told that your love "completes" your partner? & .70 & -.02 & -.07 & .46 \\
\hline Romantic partners praised your ability to take care of their emotional needs? & .65 & .26 & -.22 & .45 \\
\hline Romantic partners expected you to please them through physical intimacy? & .56 & -.09 & .10 & .44 \\
\hline $\begin{array}{l}\text { You have been made to feel that you "owed" a date something after being taken } \\
\text { out to an expensive restaurant or event? }\end{array}$ & .48 & -.12 & .27 & .61 \\
\hline $\begin{array}{l}\text { You experienced your date act in a way that protected you from being harassed } \\
\text { by other people? }\end{array}$ & .44 & .16 & .04 & .75 \\
\hline $\begin{array}{l}\text { You have been on a date and your date makes the decision where to go for } \\
\text { dinner? }\end{array}$ & .42 & -.19 & .21 & .53 \\
\hline $\begin{array}{l}\text { Others assumed that you will sacrifice your needs if it benefits your romantic } \\
\text { partner in some way? }\end{array}$ & .35 & .08 & .29 & .71 \\
\hline Your date asked you out, rather than you asking out your date? & .33 & .003 & .11 & .40 \\
\hline $\begin{array}{l}\text { Others provided you with financial support (e.g., assist with bills, pay for } \\
\text { vacation, buy drinks, pay for dates, etc.)? }\end{array}$ & .32 & -.001 & .16 & .54 \\
\hline \multicolumn{5}{|l|}{ (b) Complementary Gender Differentiation (CGD) } \\
\hline $\begin{array}{l}\text { People assumed that you will interrupt your career or educational plans to take } \\
\text { care of family needs (such as a sick family member or provide childcare)? }\end{array}$ & -.19 & .74 & .13 & .66 \\
\hline You been told that you are (or will be) a good mother because you are so caring? & .12 & .64 & -.18 & .50 \\
\hline $\begin{array}{l}\text { You have been advised to consider a career or job that allows the time to also be } \\
\text { a good mother? }\end{array}$ & -.11 & .62 & .09 & .44 \\
\hline $\begin{array}{l}\text { You have been praised for performing domestic tasks, such as cooking, cleaning, } \\
\text { and taking care of small children? }\end{array}$ & .07 & .55 & .07 & .47 \\
\hline People have expected you to display "purity" in your behaviors? & .06 & .53 & -.003 & .74 \\
\hline $\begin{array}{l}\text { People have assumed that you have strong "morals" simply because you are a } \\
\text { woman? }\end{array}$ & .03 & .49 & .004 & .71 \\
\hline $\begin{array}{l}\text { You have been informed that as a woman, you have a more refine sense of } \\
\text { culture and tastes than do men? }\end{array}$ & -.008 & .41 & .08 & .60 \\
\hline \multicolumn{5}{|l|}{ (c) Protective Paternalism (PP) } \\
\hline People questioned your ability to handle situations by yourself? & -.001 & -.07 & .70 & .63 \\
\hline $\begin{array}{l}\text { A man felt the need to explain a topic to you that you were already very } \\
\text { knowledgeable about? }\end{array}$ & -.03 & -.008 & .66 & .67 \\
\hline A man felt the need to tell you how you should run your life, do your job, etc.? & .08 & .04 & .57 & .60 \\
\hline $\begin{array}{l}\text { You have been prohibited from doing something because others (such as } \\
\text { parents or romantic partners) thought that you might get hurt? }\end{array}$ & .05 & .14 & .50 & .67 \\
\hline $\begin{array}{l}\text { Men insisted on lifting or carrying heavy things for you, even when you didn't } \\
\text { ask or need the help? }\end{array}$ & .21 & .007 & .48 & .46 \\
\hline People reminded you to look for a romantic partner who can provide financially? & -.009 & .29 & .39 & .60 \\
\hline People said that you need to be protected or have a "protector" in your life? & .05 & .32 & .37 & .78 \\
\hline $\begin{array}{l}\text { You have been offered an escort, even though you didn't feel it was necessary, } \\
\text { when walking alone at night? }\end{array}$ & -.03 & .18 & .36 & .64 \\
\hline
\end{tabular}


The factor loadings for Study 1 are from an Exploratory Factor Analysis (EFA); for Study 2, from a Confirmatory Factor Analysis (CFA)

HI, Heterosexual Intimacy; CGD, Complementary Gender Differentiation; PP, Protective Paternalism

The first factor consisted of ten items and had an initial eigenvalue of 7.55 (rotation sums of square loading total $=5.20$ ). These items were consistent with the Heterosexual Intimacy subcomponent of benevolent sexism and so the factor was labelled such. These items all pertained to experiences in the context of a romantic relationship including items such as romantic partners expecting and praising them for their ability to take care of their needs, being told their love completes their partner, and being put on a romantic pedestal by their romantic partner. As highlighted by ambivalent sexism theory (Glick and Fiske 1996), these experiences appear on the surface to romanticize men's need for women as romantic partners, yet they also promote the idea that the man is in charge of the relationship and the woman in return must fulfill the partner's needs or owes him something in return for the adoration. The Cronbach alpha for this factor was .81.

The second factor consisted of seven items and had an initial eigenvalue of 1.82 (rotation sums of square loading total $=5.40$ ). These experiences are consistent with the Complementary Gender Differentiation aspect of benevolent sexism (Glick and Fiske 1996), and the factor was given that label. The items on this component consisted of desired traits ("purity in behaviors," morality, and cultured) for a "good woman." Items on this subscale also included experiences that assumed women's most important role, and goal, is motherhood, and they should be willing to sacrifice career or education to focus on motherhood. This set of items has a subjectively positive feel to them and highlights the ways in which women are expected to complement men, although these traits can also be used to justify women's submissive, supportive role to men. The Cronbach alpha was .79.

The third factor consisted of eight items and had an initial eigenvalue of 1.40 (rotation sums of square loading total $=5.42$ ). This subscale was labelled "Protective Paternalism." The items on this component all referred to experiences where women were told they needed to be protected, were helped when it was not needed or requested, or had someone question their ability to make decisions about their life. These items are theoretically consistent with the protective paternalism aspect of benevolent sexism (Glick and Fiske 1996). The Cronbach alpha was .84.

Given the substantial sample size of women who indicated their sexual orientation as anything other than completely heterosexual ( $n=105$ ), we ran the EFA again to confirm that the scale structure was stable when examining only heterosexual women $(n=384)$. The scale still displayed a three-factor solution, and all items remained on the factors as with the entire sample.

Frequency of lifetime experience subscale scores were computed by taking the mean of the items that fell on the respective scales. As we expected, the three subscales were positively correlated (see Table 2 ). Subscale scores were also computed by taking the mean of the items that fell on the respective components for the last-year (Cronbach alphas: Complementary Gender Differentiation $=.79$, Protective Paternalism $=.83$ and Heterosexual Intimacy $=.81$ ), sexist, and distress versions of the scale. The scores for the last year subscales were very highly correlated with the scores for their counterpart's lifetime version (all $r s>.90)$. Given the near perfect correlation between the scores for the year and lifetime experiences, we do not further report analyses with the last-year version. 
Table 2 Correlations between lifetime benevolent sexist experience subscale scores, Studies 1 and 2

\begin{tabular}{|l|l|l|l|}
\hline & Correlations & & \\
\hline & $\mathbf{1}$ & $\mathbf{2}$ & $\mathbf{3}$ \\
\hline 1. Heterosexual intimacy & - & $.58^{* *}$ & $.49 * *$ \\
\hline 2. Protective paternalism & $.73^{* *}$ & - & $.61^{* *}$ \\
\hline 3. Complementary gender differences & $.72^{* *}$ & $.66^{* *}$ & - \\
\hline
\end{tabular}

Results for Study 1 are reported above the diagonal; for Study 2, below

${ }^{*} p<.05 .{ }^{* *} p<.01$

\section{Experiences with Benevolent Sexism}

Three repeated measures ANOVAs with Bonferroni-corrected post hoc tests were computed for young women's benevolently sexist experiences in the lifetime, perception of distress, and ratings of sexism (see Table $\underline{3}$ a). For frequency of experiences in the lifetime, women reported experiencing Complementary Gender Differentiation most frequently followed by Protective Paternalism, and Heterosexual Intimacy was experienced least frequently, $F(2,976)=107.57, p<.01, n p^{2}=.18$. Regarding distress, women reported feeling the most distress from Protective Paternalism, followed by Heterosexual Intimacy, and the least distress from Complementary Gender Differentiation experiences, $F(2,976)=60.29, p<.001, n p^{2}=.25$. Finally, for ratings of perceived sexism, women rated Protective Paternalism as the most sexist followed by Complementary Gender Differentiation and Heterosexual Intimacy experiences, $F(2,976)=51.75, p<.01, \eta p^{2}=.10$.

Table 3 Mean differences between benevolent sexism subscales for lifetime frequency, ratings of distress, and ratings of sexism

\begin{tabular}{|c|l|l|l|}
\hline & Complementary gender differentiation & Heterosexual intimacy & Protective paternalism \\
\hline (a) Study 1 & & & \\
\hline Lifetime & $3.59(.97)_{\mathrm{a}}$ & $2.99(.97)_{\mathrm{b}}$ & $3.30(.97)_{\mathrm{c}}$ \\
\hline Distress & $2.81(.77)_{\mathrm{a}}$ & $3.02(.97)_{\mathrm{b}}$ & $3.26(.80)_{\mathrm{c}}$ \\
\hline Sexism & $3.30(.81)_{\mathrm{a}}$ & $3.03(.99)_{\mathrm{b}}$ & $3.41(.87)_{\mathrm{c}}$ \\
\hline (b) Study 2 & & & \\
\hline Lifetime & $3.06(1.21)_{\mathrm{a}}$ & $3.09(1.06)_{\mathrm{a}}$ & $3.07(1.16)_{\mathrm{a}}$ \\
\hline Distress & $1.86(1.06)_{\mathrm{a}}$ & $1.87(.94)_{\mathrm{a}}$ & $2.24(1.12)_{\mathrm{b}}$ \\
\hline Sexism & $2.18(1.31)_{\mathrm{a}}$ & $1.95(1.03)_{\mathrm{b}}$ & $2.56(1.31)_{\mathrm{c}}$ \\
\hline
\end{tabular}

Different subscripts across each row indicate significant differences, $p<.05$ (with a Bonferroni correction)

We also compared women who indicated they were heterosexual to all other women for their reported frequency, distress, and perceived sexism ratings. None of these comparisons was significant.

Comparison of Experiences with Hostile and Benevolently Sexist Events

To compare young women's experiences with hostile and benevolent sexism, we computed total scores for the Schedule of Sexist Events, Experiences with Benevolent Sexism, and assessment of distress and perceived sexism (for both hostile and benevolent scales). Paired $t$-tests indicated that, in their lifetime, women reported experiencing more benevolently sexist events $(M=3.25, S D=.81)$ than hostile sexist events $(M=2.55, S D=.70), t(488)=24.22, p<.01$, Cohen's $d=1.08$. However, participants reported that the hostile events from the Schedule of Sexist Events $(M=4.04, S D=.73)$ were more distressing than their experiences with benevolent sexism $(M=3.05, S D=.69), t(488)=-30.98, p<.01$, Cohen's $d=1.40$. Participants also perceived the hostile events from the Schedule of Sexist Events $(M=4.34, S D=.70)$ as more sexist than their experiences with benevolent sexism $(M=3.23, S D=.76), t(488)=-35.89, p<.01$, Cohen's $d=1.63$. 
Associations between Experiences with Benevolent and Hostile Sexism and Self-Concept Correlations between the Experiences with Benevolent Sexism subscales and the self-concept measures are presented in Table 4 a. Multiple regressions were computed to predict self-esteem and self-doubt using the three Experiences with Benevolent Sexism subscales and the Schedule of Sexist Events included as predictors (see Table $\underline{5}$ a). We used the total score for the Schedule of Sexist Events because we were interested in seeing if experiences with benevolent sexism predicted self-esteem and self-doubt above and beyond the hostile sexist experiences. We also initially included sexual orientation as a variable (and interactions between the sexual orientation and benevolent sexism subscales) in the regression models. The sexual orientation variable and interaction terms were nonsignificant and so were removed from the final analyses presented here.

Table 4 Correlations between experiences with sexism and self-concept

\begin{tabular}{|c|c|c|c|c|c|c|}
\hline & Correlations & & & & & \\
\hline & Self-esteem & $\begin{array}{l}\text { Self- } \\
\text { doubt }\end{array}$ & $\begin{array}{l}\text { Judgement } \\
\text { self-doubt }\end{array}$ & $\begin{array}{l}\text { Psychological } \\
\text { well-being }\end{array}$ & $\begin{array}{l}\text { Psychological } \\
\text { flourishing }\end{array}$ & $\begin{array}{l}\text { Authoritarian } \\
\text { behavior } \\
\text { inventory }\end{array}$ \\
\hline \multicolumn{7}{|l|}{ (a) Study 1} \\
\hline $\begin{array}{l}\text { Complementary gender } \\
\text { differentiation }\end{array}$ & -.01 & .04 & -.02 & & & \\
\hline Heterosexual intimacy & -.07 & .07 & .04 & & & \\
\hline Protective paternalism & $-.13^{* *}$ & $.16^{* *}$ & $.12 *$ & & & \\
\hline Schedule of sexist events & $-.14^{* *}$ & $.18^{* *}$ & .04 & & & \\
\hline \multicolumn{7}{|l|}{ (b) Study 2} \\
\hline $\begin{array}{l}\text { Complementary gender } \\
\text { differentiation }\end{array}$ & .06 & -.04 & -.03 & .06 & $.14^{*}$ & .10 \\
\hline Heterosexual intimacy & -.07 & .08 & .07 & -.02 & .02 & -.06 \\
\hline Protective paternalism & $-.15^{*}$ & $.18 * *$ & .12 & $-.15^{*}$ & -.07 & $-.16 *$ \\
\hline Schedule of sexist events & $-.23 * *$ & $.20 * *$ & $.16 *$ & $-.26 * *$ & $-.20 * *$ & $-.41 * *$ \\
\hline
\end{tabular}

${ }^{*} p<.05 .{ }^{* *} p<.01$

Table 5 Regressions for lifetime experiences with sexism

\begin{tabular}{|c|l|l|l|l|l|l|}
\hline & $\begin{array}{l}\text { Self- } \\
\text { esteem } \\
\beta\end{array}$ & $\begin{array}{l}\text { Self- } \\
\text { doubt } \\
\beta\end{array}$ & $\begin{array}{l}\text { Judgement } \\
\text { self-doubt } \\
\beta\end{array}$ & $\begin{array}{l}\text { Psychological } \\
\text { well-being } \beta\end{array}$ & $\begin{array}{l}\text { Psychological } \\
\text { flourishing } \beta\end{array}$ & $\begin{array}{l}\text { Authoritarian } \\
\text { behavior } \\
\text { inventory } \beta\end{array}$ \\
\hline $\begin{array}{c}\text { (a) Study 1 } \\
\begin{array}{c}\text { Complementary gender } \\
\text { differentiation }\end{array}\end{array}$ & $.14^{*}$ & $-.13^{*}$ & $-.14^{*}$ & & & \\
\hline Heterosexual intimacy & -.002 & -.04 & -.02 & & & \\
\hline Protective paternalism & -.13 & $.15^{*}$ & $.23^{* *}$ & & & \\
\hline Schedule of sexist events & $-.12^{*}$ & $.16^{* *}$ & -.03 & & & \\
\hline (b) Study 2 & & & & & & \\
\hline $\begin{array}{c}\text { Complementary gender } \\
\text { differentiation }\end{array}$ & $.32^{* *}$ & $-.30^{* *}$ & $-.23^{*}$ & $.25^{*}$ & $.34^{* *}$ & $.35^{* *}$ \\
\hline Heterosexual intimacy & -.02 & .006 & .04 & .10 & .007 & -.07 \\
\hline Protective paternalism & $-.27^{*}$ & $.30^{* *}$ & .18 & $-.27^{*}$ & -.20 & -.10 \\
\hline Schedule of sexist events & $-.18^{*}$ & .13 & .12 & $-.23^{*}$ & $-.20^{*}$ & $-.44^{* *}$ \\
\hline
\end{tabular}

${ }^{*} p<.05 .{ }^{* *} p<.01$

For self-esteem, the regression model was statistically significant, $F(4,484)=4.06, p<.01, R^{2}=.03$, with the Schedule of Sexist Events $(\beta=-.12, p=.048)$ negatively associated with self-esteem and Complementary Gender Differentiation ( $\beta=.14, p=.02$ ) was positively associated with self-esteem. Protective Paternalism $(\beta=-.13, p=.05)$ and Heterosexual Intimacy $(\beta=-.002, p=.97)$ were not significant predictors. 
For self-doubt, the regression model was statistically significant, $F(4,484)=5.92, p<.01, R^{2}=.05$, with the Schedule of Sexist Events $(\beta=.16, p<.01)$ and Protective Paternalism $(\beta=.15, p=.02)$ both positively associated with self-doubt and Complementary Gender Differentiation ( $\beta=-.13, p=.03$ ) negatively associated. Heterosexual Intimacy $(\beta=-.04, p=.51)$ was not a significant predictor.

For judgmental self-doubt, the regression model was statistically significant, $F(4,484)=3.46, p=.01, R^{2}=.03$, with Protective Paternalism $(\beta=.23, p<.01)$ positively and Complementary Gender Differentiation $(\beta=-.14, p=.02)$ negatively associated with self-doubt. Heterosexual Intimacy $(\beta=.02, p=.76)$ and the Schedule of Sexist Events $(\beta=-.03, p=.67)$ were not significant predictors.

\section{Discussion}

In this first study we sought to develop and provide initial validity tests of a measure of women's benevolently sexist experiences that is consistent with the three components of benevolent sexism (Heterosexual Intimacy, Complementary Gender Differentiation, and Protective Paternalism) as outlined by ambivalent sexism theory (Glick and Fiske 1996). The three subscales derived from the exploratory factor analysis demonstrate adequate reliability and are positively inter-correlated. Women report experiencing benevolently sexist events more frequently, but as less sexist and distressing, than overtly hostile sexist events. This is consistent with research suggesting that women often fail to identify these behaviors as stemming from sexism (Barreto and Ellemers 2005; Killianski and Rudman 1998) and underestimate the amount of distress resulting from benevolently sexist experiences (Bosson et al. 2010).

Consistent with previous research, experiencing the overtly sexist behaviors on the Schedule of Sexist Events (e.g., Klonoff and Landrine 1995) is negatively associated with self-esteem and positively associated with selfdoubt. A similar pattern was found for Protective Paternalism, which is consistent with experimental research that protective paternalism is associated with negative outcomes for women, including doubting one's skills and feelings of incompetence (Dumont et al. 2010; Gervais and Vescio 2012; Shepherd et al. 2011). In contrast, whereas Complementary Gender Differentiation is not associated with self-doubt in the zero order-correlations, it is negatively associated with self-doubt and positively associated with self-esteem in the regressions. This finding is surprising to the extent that one would expect experiencing sexism to take a toll on women's selfconcept. However, we suspect this is because Complementary Gender Differentiation experiences consist of being praised and rewarded for engaging in gender-stereotyped behaviors. For women who meet these cultural expectations and receive that praise (even if these expectations are perceived as sexist) these experiences may serve to boost one's self-esteem and decrease self-doubt. Finally, Heterosexual Intimacy experiences are reported as being experienced least frequently and perceived as the least sexist of the three subtypes, and they did not correlate with self-esteem or self-doubt.

\section{Study 2}

Our first study provided initial support for the new measure of women's experiences with benevolent sexism. However, the study was conducted on a relatively homogeneous group of young women on a private university campus. The first goal of Study 2 is to confirm the factor structure of the scale using a more diverse sample collected online using MTurk. MTurk is an online crowdsourcing service where anonymous workers complete online surveys for monetary compensation. Samples acquired through MTurk are more diverse than college samples and still produce reliable high-quality data (Buhrmester et al. 2011).

The second goal is to replicate the findings from Study 1. Consistent with those study findings, we hypothesize that women will report experiencing benevolent sexism more frequently than hostile sexism. However, they will rate hostile sexism as more distressing and sexist. We also measured women's self-doubt and self-esteem and expect to replicate the results that frequency of experiences with Protective Paternalism and the Schedule of 
Sexist Events will be positively associated with self-doubt measures and negatively with self-esteem. However, experiences with Complementary Gender Differentiation will be negatively associated with self-doubt and positively associated with self-esteem.

Third, we provide further validation of the new scale by examining how Experiences with Benevolent Sexism are associated with women's mental well-being. Well-being was measured with two scales: Psychological Well-being (Cummins et al. 2003), which measures satisfaction in domains such as health and relationships, and the Psychological Flourishing Scale (Diener et al. 2010), which assesses function in different life areas. Previous research has found that experiencing gender-based discrimination and sexist events is negatively associated with a wide range of mental health indicators (Landrine et al. 1995; Moradi and Subich 2002). Thus, we hypothesize that the Schedule of Sexist Events will be negatively associated with Psychological Well-being and Flourishing. Given the findings in Study 1, we hypothesize that frequency of experiences with Protective Paternalism will also be negatively associated with Psychological Well-being and Flourishing. However, Complementary Gender Differentiation is expected to have a positive association with Psychological Well-being and Flourishing, similar to the results from Study 1 regarding self-esteem and self-doubt. We made no hypotheses regarding the associations between Heterosexual Intimacy and well-being.

Theoretically, benevolent sexism is bestowed upon women who "stay in their place" in gender traditional roles (Glick and Fiske 1996). In experimental research, women who are exposed to benevolently sexist attitudes are more likely to justify the current gender status quo (Jost and Kay 2005). However, women who are exposed to hostile sexist attitudes are more likely to challenge the status quo (Becker and Wright 2011). Therefore, we hypothesize that experiencing all forms of benevolent sexism should be positively associated with showing deference to traditional authority figures. However, the Schedule of Sexist Events, which measures overt sexist experiences, should be negatively associated with showing deference to authority figures.

Finally, benevolent sexism often occurs within the context of romantic relationships (Hammond et al. 2016; Rudman and Glick 2008). Hammond et al. (2016) found that women who perceive their male partner to be high in benevolent sexism are more likely to personally endorse benevolently sexist attitudes and to perceive increased relationship regard and security from the male partner. Furthermore, men with strong benevolently sexist attitudes are more likely to provide female partners with dependency-oriented help (Hammond and Overall 2015; Shnabel et al. 2016). Building on this research, we sought to provide a preliminary examination of how experiences with benevolent sexism might function in relationships. We hypothesize that women who are currently in a romantic relationship will report experiencing more of all three types of benevolently sexist events than those not in a relationship. Furthermore, female participants who are in a romantic relationship were asked to report on their partner's hostile and benevolently sexist attitudes. We hypothesize that perception of the partner's benevolently sexist beliefs (while controlling for hostile sexist attitudes) will be positively associated with women's reports of the frequency of their experiences with all three types of benevolent sexism.

\section{Method}

\section{Participants}

Fully 216 U.S. women completed the survey online and are included in the analyses. Regarding ethnicity, 172 (79.6\%) identified as being White, 14 (6.5\%) as African American, 16 (7.4\%) as Latina, 17 (7.9\%) as Asian American, and $13(6 \%)$ indicated another ethnicity. Individuals could check all ethnicities that applied. The majority indicated they were heterosexual $(86 \%, n=186)$. The mean age of participants was 36.38 $(S D=11.54, M d n=34)$ and ranged from 21 to 77 years-old. 


\section{Experiences with Benevolent Sexism}

The newly developed 25-item Experiences with Benevolent Sexism Scale was used to assess the experiences women have had with benevolent sexism. The items were measured on the same scale and were presented in alternating order across the three subscales. Each item was again rated for frequency experienced in the last year, lifetime, perceived distress, and perceived sexism.

\section{Self-Doubt, Self-Esteem, and Sexist Events}

The Judgmental Self-Doubt (Mirels et al. 2002) and Self-Doubt (Oleson et al. 2000) scales used in Study 1 were again used in Study 2. The Cronbach alpha in the current study for Self-doubt was .92 and for Judgmental Selfdoubt was .97. Rosenberg's (1965) self-esteem measure was again used to assess global self-esteem. The Cronbach alpha in the current study was .94. The Schedule of Sexist Events was used again to assess women's experiences with sexism (Klonoff and Landrine 1995). The current study Cronbach alphas for lifetime, year, distress, and sexist subscales were $.94, .93, .94$, and .95 , respectively.

\section{Personal Well-Being Index}

The Personal Well-being Index assesses perceived life satisfaction in domains such as one's health, interpersonal relationships, and perceived safety (Cummins et al. 2003). Participants responded to nine items on a scale of 0 (Completely Dissatisfied) to 10 (Completely Satisfied). The items are averaged and higher scores indicate greater satisfaction. It includes items like "How satisfied are you with your standard of living?" The measure's user manual reports a Cronbach's alpha of between .70 and .85. In the current study the Cronbach alpha was .89.

\section{Psychological Flourishing Scale}

The Psychological Flourishing Scale assesses different areas of functioning (Diener et al. 2010). Items include "I am optimistic about the future" and "I lead a purposeful and meaningful life." Participants responded to the eight items on a scale of 1 (Strongly Disagree) to 7 (Strongly Agree). Items are averaged and higher scores indicate greater flourishing. It has been shown to be valid though positive correlations with other measures of well-being, such as Ryff's competency/mastery scale and the Satisfaction with Life Scale (Diener et al. 2010). The Cronbach alpha for the original scale was .87. The Cronbach alpha in the current study was .92.

\section{Authority Behavior Inventory}

The Authority Behavior Inventory (Rigby 1987) assesses acceptance and deference to authority figures. The 24items are rated on a scale of 1 (never) to 5 (very frequently). Items are averaged and higher scores indicate more deference to authority. It includes items such as "Do you listen attentively to what older people say about how you should behave?" and "When a person in authority whom you trust tells you to do something, do you do it, even though you can't see the reason for it?" Validity for the scale was supported with correlations to other measures of authority, and the Cronbach alphas ranged from .76 to .90 (Rigby 1987). In the current study the Cronbach alpha was .75.

\section{Ambivalent Sexism Inventory}

The Ambivalent Sexism Inventory assesses endorsement of sexist attitudes (Glick and Fiske 1996, 1997). It consists of two subscales: hostile ("Women seek to gain power by getting control over men") and benevolent sexism ("A good woman should be set on a pedestal by her man"). Eleven items contribute to each subscale on a scale of 0 (Strongly Disagree) to 5 (Strongly Agree). Items are averaged; higher scores indicate greater endorsement of sexist beliefs. The Cronbach alpha for the original scale development ranged from .80 to .92 for hostile sexism and .73 to .85 for benevolent sexism. The current study asked participants to respond to the items as they believed their partners would respond: 0 (Partner Would Strongly Disagree) to 5 (Partner Would Strongly Agree). Previous research found that women's reports of their partner's ambivalently sexist attitudes were positively correlated with the partner's self-reports of their beliefs (Hammond et al. 2016). The 
Cronbach alpha for the current study was .93 for perceived hostile sexism and .84 for perceived benevolent sexism.

\section{Procedure}

Women were recruited to participate in the survey through MTurk Prime and offered \$1 for their participation. All surveys were completed online at a time and location of the participant's choice. One validity check item was randomly presented in the surveys. This question instructed participants to select a specific answer, and all participants correctly answered this question. Surveys were presented randomly via Qualtrics except for the participant's report of their romantic partner's ambivalent sexism. Participants were first asked if they were currently in a romantic relationship that was ongoing for at least 4 months. If yes, they indicated the relationship status (married, dating, etc.) and then completed the ambivalent sexism survey for perceptions of partner's beliefs. This survey was completed right before the demographics at the end of the study to ensure that participants only reported on their perceptions of their partner's beliefs for that one survey. Demographic items were completed last.

The mean completion time for the study was $28.38 \mathrm{~min}(S D=36.96, M d n=24.07 \mathrm{~min})$. Four participants were removed from the dataset due to unreasonably fast completion time (defined as less than one third of the median completion time). Five participants were removed because the MTurk gender consistency measure (provided by MTurk) indicated that across other survey assignments they did not consistently indicate their gender was female. Three people were removed because they had excessive missing data. This resulted in the final reported sample of 216 participants.

\section{Results}

\section{Confirmatory Factor Analysis}

We conducted a confirmatory factor analysis using AMOS v.22 to confirm the scale model fit with the items completed for experiences in the lifetime because examination of the item distributions indicated that they were more normally distributed than the last-year items. The model was specified with three latent variables, with the observed variables identified in the previous study. The latent variables were allowed to correlate. For identification purposes, the path of one measured variable for each latent variable was set to one (Arbuckle and Wothke 1999). Error terms were allowed to correlate between items that had similar structure and thematic topic (see the online supplement).

In interpreting the model, we examined the item estimates, root mean square error of approximation (RMSEA), $\chi^{2}$, and overall fit index. As recommended, we also looked at the $\chi^{2}$ to degrees of freedom ratio, where it has been suggested that a ratio of either 2 to 1 or 3 to 1 indicates an acceptable fit (Arbuckle and Wothke 1999; Ullman 1996). We considered the following general guidelines that an RMSEA less than .05 indicates a "good fit" and less than .08 indicates an "acceptable fit," (McDonald and Ho 2002) and goodness of fit statistics should generally be larger than .90 (Hu and Bentler 1999; McDonald and Ho 2002).

The model resulted in a $\chi^{2}(257)=435.77, p<.01, \chi^{2} / \mathrm{df}$ ratio $=1.70, \mathrm{CFI}=.91$, and RMSEA $=.057$ with a $90 \% \mathrm{Cl}$ $[.048, .066]$. All items had statistically significant parameters on the designated factor, $p<.01$ (see Table $\underline{1}$ b), indicating that the items were designated onto the correct factors. The Chi Square to $\mathrm{df}$ ratio, relatively small residuals, and fit index suggest that the three-factor structure was an adequate approximation of the data. Cronbach coefficient alphas suggest internal reliability in the subscales: Heterosexual Intimacy $=.82$, Protective Paternalism $=.85$, and Complementary Gender Differentiation $=.81$. The subscales were again positively intercorrelated (see Table 2). The reports for lifetime and last year experiences were highly correlated $(r s>.73)$. 


\section{Experiences with Sexism}

The repeated-measures ANOVA comparing women's lifetime frequency of experiencing the three types of sexism was not significant, $F(2,430)=.10, p=.90)$, indicating that all three benevolent sexism types were experienced at similar frequency (see Table $\underline{3} b$ ). For perception of distress the ratings differed significantly with Protective Paternalism being perceived as more distressing than both Complementary Gender Differentiation and Heterosexual Intimacy (which did not differ from each other), $F(2,430)=58.11, p<.001, \eta p^{2}=.21$. For ratings of sexism, Protective Paternalism was rated as most sexist followed by Complementary Gender Differentiation and Heterosexual Intimacy, $F(2,430)=72.15, p<.01, n p^{2}=.25$.

Comparing lifetime experiences with hostile and benevolent sexism indicates that overall women experienced more benevolent sexism $(M=3.03, S D=1.03)$ than hostile sexism $(M=2.59, S D=1.06), t(214)=6.14, p<.01$, Cohen's $d=.42$. However, women reported the hostile experiences as more distressing $(M=2.79, S D=1.31)$ than the benevolent sexist experiences $(M=2.00, S D=.99), t(214)=-12.48$, Cohen's $d=.88$. Similarly, women reported the hostile events as more sexist $(M=3.02, S D=1.40)$ than the benevolent sexist experiences $(M=2.21, S D=1.13), t(214)=-12.43, p<.001$, Cohen's $d=.84$.

Examination of the means for frequency of lifetime experiences, ratings of distress, and sexism across Study 1 (college student sample) and Study 2 (online sample) suggested some interesting differences. Independent sample $t$-tests indicated that the college sample reported experiencing Complementary Gender Differentiation, $t(703)=-6.22, p<.01$, and Protective Paternalism, $t(703)=-2.80, p<.01$, more than the online sample. There was no difference between the samples for experiences with Heterosexual Intimacy, $t(703)=1.18, p=.24$, and the Schedule of Sexist Events, $t(702)=.52, p=.61$. However, the college sample reported higher levels of distress and ratings of sexism for Complementary Gender Differentiationdistress: $t(703)=-13.41, p<.01$; sexist: $t(703)=-13.87, p<.01$; Heterosexual Intimacydistress: $t(703)=-14.65, p<.01$; sexist: $t(703)=-13.15, p<.01$; Protective Paternalism distress: $t(703)=-13.60, p<.01$; sexist: $t(703)=-10.12, p<.01$; and the Schedule of Sexist Eventsdistress: $t(703)=-16.15, p<.01$; sexist: $t(703)=-16.61, p<.01)$.

Validity Analyses

Zero-order correlations between the Experiencing Benevolent Sexism lifetime frequency subscales, Schedule of Sexist Events (lifetime), and the measures of interest are presented in Table $\underline{4} \mathrm{~b}$. Protective paternalism was negatively correlated with self-esteem, psychological well-being, and the authoritarian behavior inventory, but positively correlated with self-doubt. Complementary Gender Differentiation was positively correlated with psychological flourishing, but not significantly correlated with the other variables. Heterosexual Intimacy did not have any significant correlations. The Schedule of Sexist Events was negatively correlated with self-esteem, psychological well-being, psychological flourishing, and the authoritarian behavior inventory, as well as was positively correlated with self-doubt and judgmental self-doubt. The multiple regression findings are presented in Table $\underline{5} b$.

\section{Experiencing Sexism and Self-Concept}

We sought to replicate the findings with the self-concept measures of self-esteem, self-doubt, and judgmental self-doubt from Study 1 . For self-esteem, the regression model was statistically significant, $F(4$, $210)=6.17, p<.01, R^{2}=.11$, with the Schedule of Sexist Events $(\beta=-.18, p=.03)$ and Protective Paternalism $(\beta=-.27, p=.02)$ being negatively associated, but Complementary Gender Differentiation $(\beta=.32, p<.01)$ positively associated with self-esteem. Heterosexual Intimacy was not significantly associated $(\beta=-.02, p=.85)$. For judgmental self-doubt, Complementary Gender Differentiation $(\beta=-.23, p=.03)$ was negatively associated, $F(4,210)=2.99, p=.02, R^{2}=.05$. Heterosexual Intimacy $(\beta=.04, p=.71)$, Protective Paternalism $(\beta=.18, p=.11)$, and the Schedule of Sexist Events $(\beta=.12, p=.14)$ were not significant predictors. For self- 
doubt, Complementary Gender Differentiation $(\beta=-.30, p<.01)$ was negatively associated and Protective Paternalism ( $\beta=.30, p<.01$ ) was positively associated, $F(4,210)=5.54, p<.01, R^{2}=.10$. Heterosexual Intimacy $(\beta=.006, p=.95)$ and the Schedule of Sexist Events $(\beta=.13, p=.10)$ were not significant predictors of self-doubt.

\section{Experiencing Sexism and Well-Being}

The Schedule of Sexist Events was associated with psychological flourishing ( $\beta=-.20, p=.01$ ) whereas Complementary Gender Differentiation $(\beta=.34, p<.01)$ was positively associated, $F(4$, $209)=6.22, p<.01, R^{2}=.11$. Heterosexual Intimacy $(\beta=.007, p=.95)$ and Protective Paternalism $(\beta=-.20, p=.07)$ were not significant predictors of psychological flourishing. Psychological well-being was negatively associated with Protective Paternalism $(\beta=-.27, p=.02)$ and the Schedule of Sexist Events $(\beta=-.23, p<.01)$ but was positively associated with Complementary Gender Differentiation $(\beta=25, p=.01)$, and not associated with Heterosexual Intimacy $(\beta=.10, p=.37), F(4,210)=6.72, p<.01, R^{2}=.11$.

\section{Deference to Authority}

Deference to authority was positively associated with Complementary Gender Differentiation $(\beta=.35, p<.01)$ but negatively associated with the Schedule of Sexist Events $(\beta=-.44, p<.01)$, and not associated with Heterosexual Intimacy $(\beta=-.07, p=.49)$ or Protective Paternalism $(\beta=-.10, p=.35), F(4$, 210) $=15.57, p<.01, R^{2}=.23$.

\section{Perceptions of Partner's Ambivalent Sexism and Experiences with Benevolent Sexism} Fully 172 (80\%) women reported currently being in a romantic relationship (68 were dating or engaged and 103 were married; Mean length $=120$ months, $S D=94$, range from 4 to 482 months) and 44 (20\%) were not currently in a romantic relationship. For this set of analyses, we used experiences with benevolent sexism that occurred in the last year because this timeframe was deemed more appropriate and relevant.

A MANOVA with the three benevolent sexism subscales and Schedule of Sexist Events was significant (Wilkes Lambda $=.77), F(8,418)=7.14, p<.01, n p^{2}=.12$. Follow up ANOVAS with Tukey post hoc tests $(p<.05)$ were examined. Heterosexual Intimacy experiences significantly differed across the three groups, $F(2$, $212)=18.09, p<.01, n p^{2}=.15$. Women who were married $(M=2.47, S D=1.03)$ or in a dating relationship $(M=2.63, S D=.99)$ did not differ, but both groups reported more heterosexual intimacy experiences than did women who were not in a relationship $(M=1.55, S D=.83)$. Similar findings were found for Complementary Gender Differentiation, $F(2,212)=7.81, p<.01, n p^{2}=.07$, where women who were married $(M=2.55, S D=1.17)$ or in a dating relationship $(M=2.57, S D=1.11)$ did not differ, but both groups experienced significantly more of these experiences than women who were not in a relationship $(M=1.81, S D=.96)$. Similarly, for Protective Paternalism, $F(2,212)=6.70, p<.01, n p^{2}=.06$, women who were married $(M=2.22, S D=1.10)$ or in a dating relationship $(M=2.62, S D=1.21)$ did not differ from each other. Women who were dating experienced more Protective Paternalism than did women who were single $(M=1.86, S D=.85)$. For the Schedule of Sexist Events, $F(2,212)=5.64, p<.01, n p^{2}=.05$, women who were in a dating relationship reported experiencing more sexist events $(M=2.13, S D=.92)$ than did women who were married $(M=1.71, S D=.82)$ or not in a romantic relationship $(M=1.74, S D=.81)$.

Multiple regressions were computed using perception of the partner's hostile and benevolently sexist attitudes as the predictor variables and the benevolent sexist experience last year subscales as the outcome variables. Women's reports of their partner's benevolently sexist attitudes $(\beta=.26, p<.01)$, but not hostile attitudes $(\beta=.11, p=.14)$, was positively associated with their experiences with Complementary Gender Differentiation in the last year, $F(2,169)=9.27, p<.001, R^{2}=.10$. The same pattern of results was found for Heterosexual Intimacy, $F(2,169)=4.77, p=.01, R^{2}=.05$, where benevolently sexist attitudes $(\beta=.18, p=.02)$, but not hostile attitudes $(\beta=.10, p=.20)$, was significantly associated. The regression model was not significant for Protective 
Paternalism, $F(2,169)=1.58, p=.21, R^{2}=.02$, and neither perceptions of the partner's benevolently sexist attitudes $(\beta=.11, p=.17)$ or hostile sexist attitudes $(\beta=.06, p=.49)$ were significant predictors.

\section{Discussion}

In this second study, the scale structure is supported with the online sample and the subscales demonstrated acceptable reliability. Importantly, many of the findings are consistent with the first study. Women report experiencing benevolently sexist events more often than hostile events; however, they report these events as less sexist and distressing than the hostile events. This sample also rated Protective Paternalism experiences as the most sexist and distressing subtype of benevolent sexism. The patterns of associations with our measures of self-concept are also similar to the findings in Study 1. In the regressions, the Schedule of Sexist Events and Protective Paternalism are both positively associated with self-doubt and negatively associated with self-esteem and psychological well-being. However, experiences with Complementary Gender Differentiation is positively associated with self-esteem, psychological well-being and flourishing, increased deference to authority, and negatively associated with self-doubt. Furthermore, women who are in romantic relationships report experiencing more benevolently sexist events, and the frequency of these experiences is positively correlated with perceptions of the romantic partner's benevolently sexist attitudes.

\section{General Discussion}

The present two studies provide support for the scale structure and validity of the new Experiences with Benevolent Sexism Scale. (The full scale, along with its instructions and scoring information, can be found and downloaded from the online supplement.) The scale is theoretically consistent with ambivalent sexism theory (Glick and Fiske 1996) and provides a novel way for understanding how everyday benevolent sexism is associated with women's self-concept and well-being. Across both studies, the Schedule of Sexist Events was positive associated with increased self-doubt, decreased self-esteem, and poorer psychological well-being and flourishing. This pattern is consistent with a body of research on the negative effects of experiencing sexist events. Importantly, the benevolent sexism subscales predicted the outcomes of interest even after controlling for the more overtly sexist experiences. Across both studies, Protective Paternalism was rated as the most distressing and sexist component of benevolent sexism and stands out as most problematic for women's wellbeing. Protective Paternalism was negatively associated with our measures of self-concept and well-being. However, Complementary Gender Differentiation was positively associated with self-concept, well-being, and increased deference to authority. Heterosexual Intimacy experiences did not correlate with the self-concept or well-being measures; however, women in romantic relationships experienced this type of benevolent sexism more than women not currently in a relationship did, and the frequency of experience was positively correlated with perceptions of the partner's benevolently sexist attitudes.

\section{Comparison of the College and Online Samples}

For the college-age sample, Complementary Gender Differentiation experiences were reported as occurring the most frequently across the three types of benevolently sexist events. This is similar to Swim et al. (2001) finding that women frequently experience gender role stereotyping. However, the online sample did not differ for their frequency of experiences across the three benevolent sexism subscales. Interestingly, comparisons of the MTurk sample to the college sample suggest that college-aged women experience more Complementary Gender Differentiation and Protective Paternalism than the online sample; however, the two groups did not differ in their reports of frequency for Heterosexual Intimacy and the Schedule of Sexist Events. This may suggest that specific types of benevolent sexism may be more common among certain age groups or within certain environments. 
Furthermore, the college sample reported the events as more distressing and sexist than the MTurk sample did. It is likely that college students are more aware of these types of behaviors as sexism because of campus discussions and coursework regarding issues of sexism (Bryant 2003; Pettijohn and Walzer 2008). Examination of the MTurk sample's means highlight that this online, older sample of women does not report these experiences to be highly sexist or distressing. This is not overly surprising because previous research has found that benevolently sexist behaviors are often rated as less sexist than hostile behaviors (Chisango and Javangwe 2012; Killianski and Rudman 1998) and the perpetrators are often viewed favorably (Chisango and Javangwe 2012), making these behaviors difficult to identify as sexist. Furthermore, even for the more overtly hostile sexist experiences from the Schedule of Sexist events (such as being called derogatory names, being threatened with harm, denied promotions at work), the means for this group of women did not move past the midpoint for the distress and perceived sexism scales. Overall, women do not rate any of their experiences as highly sexist or distressing.

\section{Associations with Self-Concept and Well-Being}

Given that women do not appraise these benevolently sexist experiences as highly distressing or sexist, one might argue that they are not problematic. The correlations suggest otherwise. Experiencing Protective Paternalism was associated with lower self-esteem and psychological well-being as well as positively associated with increased self-doubt. Although many of these behaviors, on the surface, seem innocuous and even friendly (e.g., helping and providing women with financial support), they also convey a message that women are unable to do these things for themselves. This is consistent with other research that has found dependency-oriented helping serves to undercut the recipient's self-regard and feelings of competence (Hammond and Overall 2015; Shnabel et al. 2016). The current study provides correlational evidence based on women's self-reported experiences, which makes determining causality difficult. However, the findings for Protective Paternalism are consistent with experimental research that has found that experiencing benevolent sexism is associated with several negative consequences for young adult women, including doubting one's skills and feelings of incompetence (e.g., Dumont et al. 2010; Gervais and Vescio 2012; Shepherd et al. 2011). This is also consistent with research that has found that women who receive dependency-oriented support from a male partner report lower goal-related competence (Hammond and Overall 2015). Thus, there is good reason to suspect that experiencing protective paternalism has a negative impact on women's lives and sense of self.

The findings for Complementary Gender Differentiation are interesting in that they consistently showed a pattern opposite of Protective Paternalism. Although the zero-order correlations between Complementary Gender Differentiation and the various measures were not significant, when in the regression with the other forms of benevolent sexism and the Schedule of Sexist Events, these experiences became positively associated with self-esteem and well-being, as well as negatively associated with self-doubt. These findings are consistent with Oswald et al.' (2012) study where they found that experiencing benevolent sexism (measured with a revised Chivalry Scale) was positively associated with young adult women's body-esteem. Oswald and colleagues suggested that the seemingly complementary nature of benevolent sexism can serve to, at least temporarily, boost a young women's body-esteem. Recall, benevolent sexism is the "reward" given to women who meet gender traditional expectations. Thus, women who experience Complementary Gender Differentiation, along with the praise that comes with meeting gender traditional expectations, may have an increase in self-esteem and well-being.

The findings for Complementary Gender Differentiation should further be considered given that a line of research that has found a positive association between benevolently sexist attitudes and life satisfaction (Connelly and Heesacker 2012; Hammond and Sibley 2011; Napier et al. 2010). For women, this association was mediated by an increase in system justification (Connelly and Heesacker 2012; Hammond and Sibley 2011). 
Hammond and Sibley (2011, p. 339) noted that "...endorsing BS led women to be more satisfied with life because benevolently sexist attitudes rationalise existing gender inequality" (italics in the original).

In our second study, women's experiences with Complementary Gender Differentiation was positively associated with their deference to authority. That is, women who receive praise for their gender traditional traits were also more likely to be deferential to authority. In contrast, experiencing the more overtly sexist events was associated with decreased deference to authority. This is consistent with research that has found that exposing women to complementary stereotypes, like those on the scale, result in women justifying the status quo of gender-based inequality (Jost and Kay 2005) whereas experiencing more hostile events is associated with challenging the status quo (Becker and Wright 2011). We speculate that the Complementary Gender Differentiation component of benevolent sexism functions to placate women, reinforce deference to traditional authority figures, and justify the current gender status quo.

The third component of benevolent sexism is Heterosexual Intimacy. Heterosexual intimacy reflects the cultural expectation that although the woman is adored by her partner, she is simultaneously expected to place primary emphasis on fulfilling the partner's needs and play a gender traditional, submissive role in the relationship. The experiences on this subscale were perceived as least sexist and showed little association with self-doubt, psychological well-being, or deference to authority. It is possible that this component of sexism is most directly related to relationship-oriented attitudes and behaviors. Women who are in a romantic relationship report more experiences with Heterosexual Intimacy than did women who are not in a relationship. Furthermore, perception of the partner's benevolently sexist attitudes, but not hostile attitudes, was positively associated with Heterosexual Intimacy experiences. According to ambivalent sexism theory (Glick and Fiske 1996), men are driven to form close relationships with women who will fill their intimacy and reproductive needs. Glick and Fiske (1996, p. 492) note that "...benevolent sexism may be used to compensate for, or legitimate, hostile sexism ('I am not exploiting women, I love, protect and provide for them')." Women who perceive their partner to endorse benevolent sexism beliefs report feeling more positive regard from their male partner and feel more security in their relationship, presumably because these men will provide them with the love and adoration associated with benevolent sexist beliefs (Hammond et al. 2016). We speculate that it is specifically these Heterosexual Intimacy experiences that function to sustain the romantic relationship for women who have a partner they perceive as high in ambivalent sexism. Women may interpret men's engagement in these behaviors as indicators of love rather than sexism Barreto and Ellemers 2005). Future research should further examine the role and function of Heterosexual Intimacy within the context of romantic relationships.

Importantly, it is necessary to remember that all three of the subscales of benevolent sexism are strongly, positively correlated. Although Complementary Gender Differentiation is positively associated with self-esteem and negatively with self-doubt, women are also experiencing other components of benevolent sexism that are negatively associated with self-esteem and positively with increased self-doubt. Furthermore, Complementary Gender Differentiation is associated with self-esteem and self-doubt only in the regressions when the other types of sexism are being controlled, not in the zero-order correlations. Thus, we suggest caution in interpreting any of these components of benevolent sexism and their associations with women's self-concept and well-being in a simplistic manner. Rather, the complexity of women's sexist experiences should be considered.

\section{Future Research Directions}

With the development of the present scale, future research can examine how experiencingbenevolent sexism is associated with women's sense of self, life choices, and goals. Researchers should also look at the mediators and moderators of these associations. For example, does a woman's own endorsement of hostile and benevolently sexist attitudes moderate the relationship between sexist experiences and self-doubt and well-being? Shnabel et al. (2016) found that women who endorsed benevolent sexism were more likely to seek out dependency- 
oriented helping from male partners. This suggests that women's endorsement of benevolent sexist beliefs might influence how women interpret, perceive, and respond to their experiences with benevolent sexism. Likewise, when gender identity has been made salient, women are more likely to identify a partner's remarks as sexist and confront the partner (Wang and Dovidio 2017). Thus, important individual differences might explain why some women identify these experiences as sexist whereas others might interpret the same behavior positively.

The role of benevolent sexism in the context of women's employment seems especially important to examine in future research. Experiencing Protective Paternalism at work seems especially problematic because feelings of self-doubt could play an important role in job performance. Furthermore, experiencing Complementary Gender Differentiation, such as people assuming a woman will sacrifice her career for her family, may undermine women's advancement in the workplace. Together, Complementary Gender Differentiation and Protective Paternalism might function to limit women being assigned to challenging tasks or advancement in position (see also King et al. 2012). Future research should also explore if the effects of benevolent sexism depend on whether the employment context is traditionally feminine or masculine. For example, Hideg and Ferris (2016) found that endorsement of benevolently sexist beliefs was positively associated with support for employment equity but only in traditionally feminine, not masculine, positions. Perhaps Complementary Gender Differentiation might increase women's feelings of competence in traditionally feminine fields but undermine confidence in traditionally masculine fields.

Researchers should use diverse methodologies to examine women's experiences with benevolently sexist events. Longitudinal studies would be useful to understand immediate and long-term impact of these experiences on women's well-being. Daily diary studies would be useful to understand the immediate reaction to benevolently sexist events. It would be interesting to examine if women's reports of distress and perceived sexism of the event are similar when reported immediately after the event, as compared to the recollection of an event that may have occurred sometime ago, as required in a survey study. Dyadic studies would be helpful for understanding how benevolent sexist behaviors function in the context of a romantic relationship.

\section{Limitations}

The samples in these two studies consisted largely of White women. Although the items were written in an attempt to be relevant to women of various social identities, additional research should examine how women of various social groups (as well as the intersection of various social identities) experience benevolent sexism. Issues around sexual orientation are in special need of attention. Ambivalent sexism theory argues that benevolent sexism is "rooted in long-standing heterosexual interdependence between women and men" (Lee et al. 2010, p. 398). Although the development of ambivalently sexist beliefs might stem from heterosexual relations and traditional gender relations, previous research has found that both men and women can hold ambivalently sexist beliefs, with men typically endorsing these beliefs to a greater extent than women (Glick and Fiske 1996). However, previous research has largely ignored how sexual orientation might play a role in the development and expression of these attitudes, as well as the experiences of the targets. In Study 1 we found little difference between women who were classified as heterosexual and sexual minority for their experiences as the target of benevolent sexism; however, it is unclear how the women in those two categories self-identify their sexual orientation. Future research should further investigate experiences with benevolent sexism in a sample of sexual minority women.

A second consideration should be around the effect size found in the regressions. The regression models with Experience with Benevolent Sexism subscales and Schedule of Sexist Events total score as predictors were significant, but accounted for modest amounts of the total variance in the variables of interest ( $R^{2} \mathrm{~s}$ ranging from .03 to .23$)$. Interestingly, the sexism variables accounted for more variance in deference to authority $\left(R^{2}=.23\right)$ 
than in self-esteem or self-doubt $\left(R^{2} s\right.$ ranging from .03 to .11$)$, as well as psychological flourishing and well-being $\left(R^{2} \mathrm{~S}=.11\right)$. Perhaps these sexist experiences might not influence how women feel about themselves globally, but rather how they feel they need to respond to, and interact with, other people.

\section{Practice Implications}

To date, a large body of research has examined how hostile and benevolently sexist attitudes correlate with a range of gender-related attitudes and beliefs. With the development of the Experiences with Benevolent Sexism scale, gender researchers can now similarly examine how women's experiences with benevolent sexism are related to various aspects of their lives, ranging from their interpersonal interactions, romantic relationships, academic choices, work experiences, and mental well-being. The current set of findings raise a host of fascinating questions for future research. We hope the development of this new scale encourages others to investigate these many future research questions of how experiences with benevolent sexism impact women's lives.

The current research also highlights that experiences with the different subcomponents of benevolent sexism have differential associations with other variables of interest. With few exceptions, research using the Ambivalent Sexism Inventory (Glick and Fiske 1996) has created a total score to assess benevolent sexist attitudes rather than examine the three benevolent sexism subcomponents independently. However, the subcomponents of benevolent sexist attitudes might be important to examine as well. For example, in one study that did examine the benevolent sexism attitude subcomponents separately, the researchers found that the Complementary Gender Differentiation attitude sub-score was positively associated with endorsing rape myths, but Protective Paternalism attitude sub-score was negatively associated with rape myth endorsement (Chapleau et al. 2007). Sexism researchers might want to further examine how the different subcomponents of benevolently sexist attitudes function rather than always using a total score.

Healthcare professionals and psychologists should be aware of the range of types of sexism to improve treatment for women who are experiencing sexism in their lives. Understanding the complex ways in which these experiences are related to women's mental health and life choices can be used to assist women's healthy development and facilitate their ability to identify and cope with sexism. In a daily diary study, Becker and Swim (2011) found that having women pay attention to sexism in their personal life led to rejection of benevolent sexist beliefs and more negative evaluations of men who displayed benevolent sexism. This paradigm seems especially useful for helping women to recognize the impact of benevolent sexism in their lives. We ultimately hope that this line of research helps women to identify, understand, and cope with the various forms of sexism that they experience.

Finally, increased awareness of how sexist attitudes can be manifested in subtle behaviors, whether it be in interpersonal relationships or work situations, can result in greater gender equality. Men's attention to sexism also resulted in stronger rejection of sexist attitudes, if they were also encouraged to have emotional empathy for the target of sexism (Becker and Swim 2011). Similarly, students who have taken classes that cover issues of gender and sexism report lower endorsement of sexist beliefs at the end of the semester (Pettijohn and Walzer 2008). Perhaps with education and public awareness women will ultimately experience less sexism in their lives.

\section{Conclusion}

Women report frequent sexist experiences that range from overtly sexist to subtle benevolently sexist events (Klonoff and Landrine 1995; Swim et al. 2001). Building on a large body of research that investigates ambivalently sexist attitudes (Glick and Fiske 1996), and specifically the benevolent sexism subcomponent, the current studies validated a new measure of women's experiences with benevolent sexism. Our research fills an 
important gap in the sexism literature by shifting the research question from examining sexist attitudes to focusing on women's experiences with sexist events. We find that women report having a number of sexist experiences that reflect protective paternalism, heterosexual intimacy, and complementary gender differentiation. These experiences are more frequent, but perceived as less sexist and distressing, than hostile sexist experiences. However, frequency of benevolent sexist experiences had interesting and complex associations with women's self-concept. The findings of the current studies support the use of this new measure and highlight numerous research questions regarding women's experiences with benevolent sexism. We hope this research inspires others to pursue this topic.

\section{Notes}

\section{Acknowledgements}

The authors thank Steve Franzoi and Kristine Chapleau for their helpful comments on this manuscript and feedback on item development. Thank you to Brooke Magnus for her assistance with the confirmatory factor analysis.

\section{Compliance with Ethical Standards}

This study was approved by the institutional review board at Marquette University and conforms to the APA research ethics. All authors have read and approve of submitting the manuscript to Sex Roles. This manuscript has not been published, in any part, elsewhere. This manuscript has not received any grant funding.

\section{References}

1. Abrams, D., Viki, G. T., Masser, B., \& Bohner, G. (2003). Perceptions of stranger and acquaintance rape: The role of benevolent and hostile sexism in victim blame and rape proclivity. Journal of Personality and Social Psychology, 84(1), 111-125. https://doi.org/10.1037/0022-3514.84.1.111.

2. Arbuckle, J. L., \& Wothke, W. (1999). AMOS 4.0 User's guide. Chicago IL: Small Waters Corporation.

3. Baalbaki, M., \& Oswald, D. L. (2017, March). College women write about sexism: What does it look like? Where does it happen? How do they respond? Poster presented at the 2017 Association for Women in Psychology Meetings, Milwaukee, WI.

4. Barreto, M., \& Ellemers, N. (2005). The burden of benevolent sexism: How it contributes to the maintenance of gender inequalities. European Journal of Social Psychology, 35, 633-

642. https://doi.org/10.1002/ejsp.270.

5. Barreto, M., Ellemers, B., Piebinga, L., \& Moya, M. (2010). How nice of us and how dumb of me: The effect of exposure to benevolent sexism on women's task and relational self-descriptions. Sex Roles, 62, 532544. https://doi.org/10.1007/s11199-009-9699-0.

6. Becker, J. C., \& Swim, J. K. (2011). Seeing the unseen: Attention to daily encounters with sexism as way to reduce sexist beliefs. Psychology of Women Quarterly, 35, 227-

242. https://doi.org/10.1177/0361684310397509.

7. Becker, J. C., \& Wright, S. C. (2011). Yet another dark side of chivalry: Benevolent sexism undermines and hostile sexism motivates collective action for social change. Journal of Personality and Social Psychology, 101, 62-77. https://doi.org/10.1037/a0022615.

8. Becker, J. C., Glick, P., llic, M., \& Bohner, G. (2011). Damned if she does, damned if she doesn't: Consequences of accepting versus confronting patronizing help for the female target and male actor. European Journal of Social Psychology, 41, 761-773. https://doi.org/10.1002/ejsp.823.

9. Begany, J. J., \& Milburn, M. A. (2002). Psychological predictors of sexual harassment: Authoritarianism, hostile sexism, and rape myths. Psychology of Men \& Masculinity, 3, 119-126. https://doi.org/10.1037/15249220.3.2.119. 
10. Bosson, J. K., Pinel, E. C., \& Vandello, J. A. (2010). The emotional impact of ambivalent sexism: Forecasts versus real experiences. Sex Roles, 62, 520-531. https://doi.org/10.1007/s11199-009-9664-y.

11. Bryant, A. N. (2003). Changes in attitudes toward women's roles: Predicting gender-role traditionalism among college students. Sex Roles, 48, 131-142. https://doi.org/10.1023/A:1022451205292.

12. Buhrmester, M., Kwang, T., \& Gosling, S. D. (2011). Amazon's Mechanical Turk a new source of inexpensive, yet high-quality, data? Perspectives on Psychological Science, 6(1), 3-

5. https://doi.org/10.1177/1745691610393980.

13. Chapleau, K. M., Oswald, D. L., \& Russell, B. L. (2007). How ambivalent sexism toward women and men support rape myth acceptance. Sex Roles, 57, 131-136. https://doi.org/10.1007/s11199-007-9196-2.

14. Chisango, T., \& Javangwe, G. (2012). Are people better at recognizing ambivalent sexism on the basis of nonstandard profiles than the standard ASI ones? Sex Roles, 67, 69-82. https://doi.org/10.1007/s11199012-0146-2.

15. Connelly, K., \& Heesacker, M. (2012). Why is benevolent sexism appealing? Associations with system justification and life satisfaction. Psychology of Women Quarterly, 36, 432443. https://doi.org/10.1177/0361684312456369.

16. Cummins, R. A., Eckersley, R., Pallant, J., van Vugt, J., \& Misajon, R. (2003). Developing a national index of subjective well-being: The Australian Unity Well-being Index. Social Indicators Research, 64, 159190. https://doi.org/10.1023/A:1024704320683.

17. Diener, E., Wirtz, D., Tov, W., Kim-Prieto, C., Choi, D., Oishi, S., \& Biswas-Diener, R. (2010). New well-being measures: Short scales to assess flourishing and positive and negative feelings. Social Indicators Research, 97, 143-156. https://doi.org/10.1007/sll205-009-9493-y.

18. Donnellan, M. B., Trzesniewski, K. H., \& Robins, R. W. (2015). Measures of self-esteem. In G. J. Boyle, D. H. Saklofske, \& G. Matthews (Eds.), Personality and social psychological constructs (pp. 131-157). London, UK: Academic Press.

19. Dumont, M., Sarlet, M., \& Dardenne, B. (2010). Be too kind to a woman, she'll feel incompetent: Benevolent sexism shifts self-construal and autobiographical memories toward incompetence. Sex Roles, 62, 545553. https://doi.org/10.1007/s11199-008-9582-4.

20. Farkas, T., \& Leaper, C. (2016). Chivalry's double-edged sword: How girls' and boys' paternalistic attitudes relate to their possible family and work selves. Sex Roles, 74, 220-230. https://doi.org/10.1007/s11199015-0556-z.

21. Ford, T. E., Boxer, C. F., Armstrong, J., \& Edel, J. R. (2008). More than "just a joke": The prejudice-releasing function of sexist humor. Personality and Social Psychology Bulletin, 34, 159170. https://doi.org/10.1177/0146167207310022.

22. Gervais, S. J., \& Vescio, T. K. (2012). The effect of patronizing behaviour and control on men and women's performance in stereotypically masculine domains. Sex Roles, 66, 479491. https://doi.org/10.1007/s11199-011-0115-1.

23. Glick, P., \& Fiske, S. T. (1996). The ambivalent sexism inventory: Differentiating hostile and benevolent sexism. Journal of Personality and Social Psychology, 70, 491-512. https://doi.org/10.1037/00223514.70.3.491.

24. Glick, P., \& Fiske, S. (1997). Hostile and benevolent sexism: Measuring ambivalent sexist attitudes toward women. Psychology of Women Quarterly, 21, 119-136. https://doi.org/10.1111/i.14716402.1997.tb00104.x.

25. Glick, P., \& Fiske, S. T. (2001a). Ambivalent sexism. In M. P. Zanna (Ed.), Advances in experimental social psychology (pp. 115-188). San Francisco: Academic Press.

26. Glick, P., \& Fiske, S. T. (2001b). An ambivalent alliance. Hostile and benevolent sexism as complementary justifications for gender inequality. American Psychologist, 56, 109-118. https://doi.org/10.1037//000366X.56.2.109. 
27. Hammond, M. D., \& Overall, N. C. (2015). Benevolent sexism and support of romantic partner's goals: Undermining women's competence while fulfilling men's intimacy needs. Personality and Social Psychology, 41, 1180-1194. https://doi.org/10.1177/0146167215593492.

28. Hammond, M. D., \& Sibley, C. G. (2011). Why are benevolent sexists happier? Sex Roles, 65, 332343. https://doi.org/10.1007/s11199-011-0017-2.

29. Hammond, M. D., Sibley, C. G., \& Overall, N. C. (2014). The allure of sexism: Psychological entitlement fosters women's endorsement of sexism over time. Social Psychological and Personality Science, 5, 422429. https://doi.org/10.1177/1948550613506124.

30. Hammond, M. D., Overall, N. C., \& Cross, E. J. (2016). Internalizing sexism within close relationships: Perceptions of intimate partner's benevolent sexism promote women's endorsement of benevolent sexism. Journal of Personality and Social Psychology, 110, 214-

238. https://doi.org/10.1037/pspi0000043.

31. Hideg, I., \& Ferris, D. L. (2016). The compassionate sexist? How benevolent sexism promotes and undermines gender equality in the workplace. Journal of Personality and Social Psychology, 111, 706727. https://doi.org/10.1037/pspi0000072.

32. Hu, L., \& Bentler, P. M. (1999). Cutoff criteria for fit indexes in covariance structure analysis: Conventional criteria versus new alternatives. Structural Equation Modeling, 6, 155. https://doi.org/10.1080/10705519909540118.

33. Jones, K., Stewart, K., King, E., Morgan, W. B., Gilrane, V., \& Hylton, K. (2014). Negative consequence of benevolent sexism on efficacy and performance. Gender in Management, 29, 171189. https://doi.org/10.1108/GM-07-2013-0086

34. Jost, J. T., \& Kay, A. C. (2005). Exposure to benevolent sexism and complementary gender stereotypes: Consequences for specific and diffuse forms of system justification. Journal of Personality and Social Psychology, 88, 498-509. https://doi.org/10.1037/0022-3514.88.3.498.

35. Killianski, S. E., \& Rudman, L. A. (1998). Wanting it both ways: Do women approve of benevolent sexism? Sex Roles, 39, 333-352. https://doi.org/10.1023/A:1018814924402.

36. King, E. B., Botsford, W., Hebl, M. R., Kazama, S., Dawson, J. F., \& Perkins, A. (2012). Benevolent sexism at work: Gender differences in the distribution of challenging developmental experiences. Journal of Management, 38, 1835-1866. https://doi.org/10.1177/0149206310365902.

37. Klonoff, E. A., \& Landrine, H. (1995). The Schedule of Sexist Events: A measure of lifetime and recent sexist discrimination in women's lives. Psychology of Women Quarterly, 19, 439-

472. https://doi.org/10.1111/j.1471-6402.1995.tb00086.x.

38. Klonoff, E. A., Landrine, H., \& Campbell, R. (2000). Sexist discrimination may account for well-known gender differences in psychiatric symptoms. Psychology of Women Quarterly, 24, 93-

99. https://doi.org/10.1111/j.1471-6402.2000.tb01025.x

39. Landrine, H., \& Klonoff, E. A. (1997). Discrimination against women: Prevalence, consequences, remedies. Thousand Oaks, CA: SAGE Publications.

40. Landrine, H., Klonoff, E. A., Gibbs, J., Manning, V., \& Lund, M. (1995). Physical and psychiatric correlates of gender discrimination: An application of the Schedule of Sexist Events. Psychology of Women Quarterly, 19, 473-492. https://doi.org/10.1111/j.1471-6402.1995.tb00087.x.

41. Lee, T. L., Fiske, S. T., \& Glick, P. (2010). Next gen ambivalent sexism: Converging correlates, causality in context, and converse causality, an introduction to the special issue. Sex Roles, 62, 395404. https://doi.org/10.1007/s11199-010-9747-9.

42. LeMaire, K. L., Oswald, D. L., \& Russell, B. L. (2016). Labeling sexual victimization experiences; The role of sexism, rape myth acceptance, and tolerance for sexual harassment. Violence and Victims, 31, 332346. https://doi.org/10.1891/0886-6708.VV-D-13-00148. 
43. Masser, B., \& Abrams, D. (1999). Contemporary sexism: The relationships among hostility, benevolence and neosexism. Psychology of Women Quarterly, 23, 503-571. https://doi.org/10.1111/i.14716402.1999.tb00378.x.

44. Masser, B. M., \& Abrams, D. (2004). Reinforcing the glass ceiling: The consequences of hostile sexism for female managerial candidates. Sex Roles, 51, 609-615. https://doi.org/10.1007/s11199-004-54708.CrossRefGoogle Scholar

45. Matteson, A. V., \& Moradi, B. (2005). Examining the structure of the Schedule of Sexist Events: Replication and extension. Psychology of Women Quarterly, 29, 47-57. https://doi.org/10.1111/j.03616843.2005.00167.x.

46. McDonald, R., \& Ho, M. R. (2002). Principles and practices in reporting structural equation analyses. Psychological Methods, 7, 64-82. https://doi.org/10.1037//1082-989X.7.1.64.

47. Mirels, H. L., Greblo, P., \& Dean, J. B. (2002). Judgmental self-doubt: Beliefs about one's judgmental prowess. Personality and Individual Differences, 33, 741-758. https://doi.org/10.1016/S01918869(01)00189-1.

48. Moradi, B., \& Subich, L. M. (2002). Perceived sexist events and feminist identity development attitudes: Links to women's psychological distress. The Counseling Psychologist, 30, 4465. https://doi.org/10.1177/0011000002301003.

49. Moya, M., Glick, P., Exposito, F., de Lemus, S., \& Hart, J. (2007). It's for your own good: Benevolent sexism and women's reactions to protectively justified restrictions. Personality and Social Psychology Bulletin, 33, 1421-1434. https://doi.org/10.1177/0146167207304790.

50. Napier, J. L., Thorsisdottir, H., \& Jost, J. T. (2010). The joy of sexism? A multinational investigation of hostile and benevolent justifications for gender inequality and their relations to subjective well-being. Sex Roles, 62, 405-419. https://doi.org/10.1007/s11199-009-9712-7.

51. Oleson, K. C., Poehlmann, K. M., Yost, J. H., Lynch, M. E., \& Arkin, R. M. (2000). Subjective overachievement: Individual differences in self-doubt and concern with performance. Journal of Personality, 68, 491542. https://doi.org/10.1111/1467-6494.00104.

52. Oswald, D. L., Franzoi, S., \& Frost, K. (2012). Experiencing sexism and young women's body esteem. Journal of Social and Clinical Psychology, 31, 1112-1137. https://doi.org/10.1037/t00700-000.

53. Pettijohn, T. F., \& Walzer, A. S. (2008). Reducing racism, sexism, and homophobia in college students by completing a psychology of prejudice course. College Student Journal, 42, 459-468.

54. Rigby, K. (1987). An authority behavior inventory. Journal of Personality Assessment, 51, 615625. https://doi.org/10.1207/s15327752jpa5104 14.

55. Rosenberg, M. (1965). Society and the adolescent self-image. Princeton: Princeton University Press.

56. Rudman, L. A., \& Glick, P. (2008). The social psychology of gender. New York: The Guilford Press.

57. Russell, B. L., \& Trigg, K. Y. (2004). Tolerance of sexual harassment: An examination of gender differences, ambivalent sexism, social dominance, and gender roles. Sex Roles, 50, 565573. https://doi.org/10.1023/B:SERS.0000023075.32252.fd.

58. Sakalli-Ugurlu, N., \& Beydogan, B. (2002). Turkish college students' attitudes toward women managers: The effects of patriarchy, sexism, and gender differences. The Journal of Psychology, 136, 647656. https://doi.org/10.1080/00223980209604825.

59. Shepherd, M., Erchull, M. J., Rosner, A., Taubenberger, L., Queen, E. F., \& McKee, J. (2011). “I'll get that for you": The relationship between benevolent sexism and body self-perceptions. Sex Roles, 64, 18. https://doi.org/10.1007/s11199-010-9859-2.

60. Shnabel, N., Bar-Anan, Y., Kende, A., Bareket, O., \& Lazar, Y. (2016). Help to perpetuate traditional gender roles: Benevolent sexism increases engagement in dependency-oriented cross-gender helping. Journal of Personality and Social Psychology, 11, 55-75. https://doi.org/10.1037/pspi0000037. 
61. Silvan-Ferrero, M. P., \& Bustillos Lopez, A. (2007). Benevolent sexism toward men and women: Justifications of the traditional system and conventional gender roles in Spain. Sex Roles, 57, 607614. https://doi.org/10.1007/s11199-007-9271-8.

62. Swim, J. K., Hyers, L. L., Cohen, L. L., \& Ferguson, M. J. (2001). Everyday sexism: Evidence of its incidence, nature and psychological impact from three daily diary studies. Journal of Social Issues, 57, 3153. https://doi.org/10.1111/0022-4537.00200.

63. Swim, J. K., Mallett, R., Russo-Devosa, Y., \& Stangor, C. (2005). Judgments of sexism: A comparison of the subtlety of sexism measures and sources of variability in judgments of sexism. Psychology of Women Quarterly, 29, 406-411. https://doi.org/10.1111/j.1471-6402.2005.00240.x.

64. Ullman, J. B. (1996). Structural equation modeling. In B. Tabachnick \& L Fidell (Eds.), Using multivariate statistics (3rd ed., pp. 709-812). New York: Harper Collins. Google Scholar

65. Viki, G. T., \& Abrams, D. (2002). But she was unfaithful: Benevolent sexism and reactions to rape victims who violate traditional gender role expectations. Sex Roles, 47, 289-

293. https://doi.org/10.1023/A:1021342912248.

66. Viki, G. T., Abrams, D., \& Hutchinson, P. (2003). The "true" romantic: Benevolent sexism and paternalistic chivalry. Sex Roles, 49, 533-537. https://doi.org/10.1023/A:1025888824749.

67. Viki, G. T., Abrams, D., \& Masser, B. (2004). Evaluating stranger and acquaintance rape: The role of benevolent sexism in perpetrator blame and recommended sentence length. Law and Human Behavior, 28, 295-303. https://doi.org/10.1023/B:LAHU.0000029140.72880.69.

68. Wang, K., \& Dovidio, J. F. (2017). Perceiving and confronting sexism: The causal role of gender identity salience. Psychology of Women Quarterly, 41, 65-76. https://doi.org/10.1177/0361684316670628. 